\title{
Effects of Aluminum Particle Size, Galinstan Content and Reaction Temperature on Hydrogen Generation Rate Using Activated Aluminum and Water
}

\author{
Kandasamy Jayaraman*, Christian Chauveau, Iskender Gökalp \\ CNRS-ICARE, 1C Av. de la Recherche Scientifique, Orléans, France \\ Email: "jayaraman mit@yahoo.com, christian.chauveau@cnrs-orleans.fr, iskender.gokalp@cnrs-orleans.fr
}

Received 11 June 2015; accepted 22 August 2015; published 25 August 2015

Copyright (C) 2015 by authors and Scientific Research Publishing Inc.

This work is licensed under the Creative Commons Attribution International License (CC BY).

http://creativecommons.org/licenses/by/4.0/

(c) (i) Open Access

\begin{abstract}
Aluminum, in its normal passive oxidized state, does not react with water. In this work, aluminum activation is carried out using liquid metal eutectics Ga-In-Sn-Zn (60:25:10:5). Subsequently, the reaction with water of activated aluminum to produce hydrogen has been examined. The effects of aluminum particle size, liquid eutectics content, and reaction temperature on hydrogen production rates are investigated. The liquid eutectics interaction with aluminum is discussed and the mechanisms of liquid eutectics penetration within the Al particles have been investigated. The specific surface area of the Al particles, the mass ratio of Al to eutectics content and the reaction temperature were found to determine the hydrogen production rate and yield. It is observed that micro-aluminum particles of $\sim 30 \mu \mathrm{m}$ size display lower reaction rates and hydrogen yields than $\sim 350 \mu \mathrm{m}$ size particles.
\end{abstract}

\section{Keywords}

Hydrogen Generation, Aluminum Particles, Liquid Metal Eutectics

\section{Introduction}

Air quality concerns and global climate change risks constitute two major problems in relation with our reliance on fossil energy sources. Hydrogen holds promise to provide clean, reliable and sustainable energy supply for meeting the growing demand of energy in the future [1]. Hydrogen is a fuel with the highest energy content per

"Corresponding author.

How to cite this paper: Jayaraman, K., Chauveau, C. and Gökalp, I. (2015) Effects of Aluminum Particle Size, Galinstan Content and Reaction Temperature on Hydrogen Generation Rate Using Activated Aluminum and Water. Energy and Power Engineering, 7, 426-432. http://dx.doi.org/10.4236/epe.2015.79041 
unit mass of all known fuels, which can be used for power generation and transportation at near zero pollution. Once produced, the major problems associated with hydrogen energy are related to storage, transportation and safety considerations. Therefore, hydrogen production on demand seems to be an important aspect to minimize the problems associated with the development of hydrogen technologies.

\subsection{Hydrogen Production}

A great attention has been recently given to improve the existing hydrogen production technologies or to find new methods for hydrogen production. There are different types of methods available to produce hydrogen, such as biological processes, renewable energy sources [2]-[4], catalytic steam reforming of natural gas, naphtha and other hydrocarbons, partial oxidation of hydrocarbons, gasification of coal and biomass resources and electrolysis of water [5]-[7].

Metal particles such as Ni, Fe, V, Mn, Ti, Ag, Ca, Zn, Zr, Al, and their corresponding alloys can be potentially used to produce hydrogen through catalyst (water-soluble inorganic salts) assisted reactions in water [8]. Some lightweight meta-metals or their hydrides can produce hydrogen through reactions with water. In this method, the theoretical hydrogen production rates are as follows: $1 \mathrm{~g}$ of sodium borohydride gives $2.4 \mathrm{~L}$ of hydrogen; $1 \mathrm{~g}$ of aluminum gives $1.244 \mathrm{~L}$ with bayerite/boehmite formation; $1 \mathrm{~g}$ of magnesium gives $0.95 \mathrm{~L}$, and $\mathrm{Al}$ and $\mathrm{Mg}$ hydrides give respectively $2.24 \mathrm{~L}$ and $1.88 \mathrm{~L}$ of hydrogen. Compared to other systems, aluminium has favorable features, such as cost-effectiveness, non-reactivity at normal conditions, easy storability, safety during transportation, and non-toxicity.

\subsection{Aluminum Activation and Its Reaction with Water}

Several researchers have investigated various aluminum activation processes, such as treatment with iodine vapor, reaction at supercritical conditions, treatment of the metal surface with $\mathrm{NaOH}$ or $\mathrm{KOH}$ solutions, surface contact with activator metals (mercury, gallium, indium) and metal-alloys (gallium-indium eutectics) [9]-[11]. Activator metals remove the alumina layer and generate fractures on the aluminum core which is a potential way to enhance the reactivity of the aluminum. The mercury usage is creating health hazards and environmental problems. The gallium-indium eutectics seem to be the best choice to activate aluminum particle reactions with water.

Bennett and Pinnel [12] investigated the reactions of solid aluminum with liquid water and examined its products using X-ray diffraction, thermo-gravimetric and differential thermal (TG-DTA) analysis. Sheindlin and Zhuk [13] investigated the commercial possibility of hydrogen production using aluminum and its alloys. Wang et al. [10] analyzed the aluminum-based hydrogen production methods, their limitations and challenges for commercialization. Soler et al. [14] reported on the production of hydrogen using aluminum and aluminum alloys with aqueous alkaline solutions. Sarou-Kanian et al. [15] studied the low temperature reactivity of aluminum nano-powders with liquid water.

Kravchenko et al. [16] investigated the reaction of water with aluminum-based metal composites doped with gallium (Ga), indium (In), zinc (Zn), or tin (Sn) for hydrogen generation, using X-ray diffraction, DTA, and energy dispersive analysis (EDAX). Parmuzina and Kravchenko [17] demonstrated the method of aluminum activation by liquid eutectics Ga-In (70:30) and Ga-In-Sn-Zn (60:25:10:5) (galinstan), and the dispersion of the obtained specimens up to a particle size of $<0.25 \mathrm{~mm}$, leading to reactions with water and hydrogen production. The reaction temperature alters the resultant compounds and hydrogen yield [12]. As the reactions occur between water and aluminum at $50^{\circ} \mathrm{C}$ to $100^{\circ} \mathrm{C}$, the reaction product is noticed as "pseudoboehmite", which contains more hydroxyl ions than corresponding to $\mathrm{A} 1 \mathrm{OOH}$, i.e., the compound may vary from 1.5 to $2.5 \mathrm{H}_{2} \mathrm{O}$ per $\mathrm{A}_{2} \mathrm{O}_{3}$.

At $25^{\circ} \mathrm{C}, \quad \mathrm{Al}+3 \mathrm{H}_{2} \mathrm{O} \rightarrow \mathrm{Al}(\mathrm{OH})_{3}+3 / 2 \mathrm{H}_{2} \uparrow \quad$ (Bayerite- $\beta \mathrm{Al}_{2} \mathrm{O}_{3} \cdot 3 \mathrm{H}_{2} \mathrm{O}$, formation)

At $90^{\circ} \mathrm{C}, \mathrm{Al}+2 \mathrm{H}_{2} \mathrm{O} \rightarrow \mathrm{AlOOH}+3 / 2 \mathrm{H}_{2} \uparrow$ (Boehmite- $\alpha \mathrm{Al}_{2} \mathrm{O}_{3} \cdot \mathrm{H}_{2} \mathrm{O}$, formation)

Ilyukhina et al. [18] investigated mechanochemical activation of aluminum using gallam metals which is processed in a high-energy ball mill.

In the present study, we have chosen the galinstan (Ga-In-Sn-Zn-60:25:10:5) eutectic, which gives optimized performances over Ga-In eutectics [17]. In this paper, we have addressed some of the associated problems in this aluminum activation method, and mainly the dependency of hydrogen production rate and yield on aluminum particle sizes, aluminum and galinstan eutectic content, and reaction temperature. The paper gives further ex- 
planation on the aluminum activation and its reaction with water. The paper also examines the effects of Al particles specific surface area and galinstan eutectic content on hydrogen production rate and yield.

\section{Experimental Details}

Aluminium particles are procured from Pechiney-Hermillon Company with three ranges of initial sizes: $30 \mu \mathrm{m}$ particles in powder form, and $60 \mu \mathrm{m}$ and $350 \mu \mathrm{m}$ particles in granular form. The required amounts of Ga, In, Zn, and $\mathrm{Sn}$ are mixed to obtain the galinstan eutectic, and, $\mathrm{Al}$ particles are added in the liquid eutectic and mixing has been done using a ceramic bowl and rod to ensure proper mixing. The sample is heated up to $100^{\circ} \mathrm{C}$ in nitrogen ambience and maintained for about 1 hour. After cooling, the experiment was immediately conducted. We have used an imaging system to measure the particle size and observe eutectic-Al interactions. This system consists of a computer integrated CCD camera with lighting arrangements. When light is focused on the activated aluminum, the temperature of the sample slightly increases from the storage temperature $\left(15^{\circ} \mathrm{C}\right)$. The galinstan alloy forms cracks and penetrates inside the aluminum core (Figure 1). For the hydrogen production rate determination, we have used an experimental set-up which consists of a temperature controlled glass reactor connected with a water-filled burette for hydrogen collection. The evolution of the gas is measured with a graduated test-tube (precision $1 \mathrm{ml}$ ) authorizing the measurement of the volume versus time. The mixture temperature is also followed by a type $\mathrm{K}$ thermocouple connected to a thermograph. To carry out the reactions at high temperatures, the reactor is introduced in an oil bath. Two magnets ensure the temperature homogeneity in the reactor and in the oil bath. The activated aluminum powder $(0.1 \mathrm{~g})$ is dropped from a flexible tube into the water reactor $(25 \mathrm{ml})$. Hydrogen generating reactions start when aluminum powder comes into contact with water. The released hydrogen is collected in the water burette to measure the quantity of hydrogen. The hydrogen generation rate per gram of aluminum is then plotted.

\section{Results and Discussion}

\subsection{Crack Formation on the Activated Al Particles}

We have examined three compositions of mixtures in this study, 85\% Al-15\% galinstan eutectics, $90 \% \mathrm{Al}-10 \%$ galinstan eutectics and $95 \% \mathrm{Al}-5 \%$ galinstan eutectics by mass. The galinstan eutectic composition is fixed as Ga-In-Sn-Zn (60:25:10:5). As the temperature of the activated-aluminum particle is increased by means of lighting, cracks are initiated and propagate. This is demonstrated in Figure 1. Hugo and Hoagland [19] reported that the ductile materials exhibit brittle fracture behavior because of interactions between the solid metal and the adsorbed liquid atoms. The liquid metal embrittlement may be caused either by tensile decohesion or enhanced shear. Such an action is explained by the effect of adsorptive decrease in solid strength under the physicochemical influence of the medium. This effect is called Rebinder effect. The rate of liquid gallium penetration at the boundaries of the grains in the aluminum polycrystal can reach 0.55 to $30 \mu \mathrm{ms}^{-1}$ at temperatures close to ambient [9]. These overall effects make the aluminum particles being readily reactive with water.

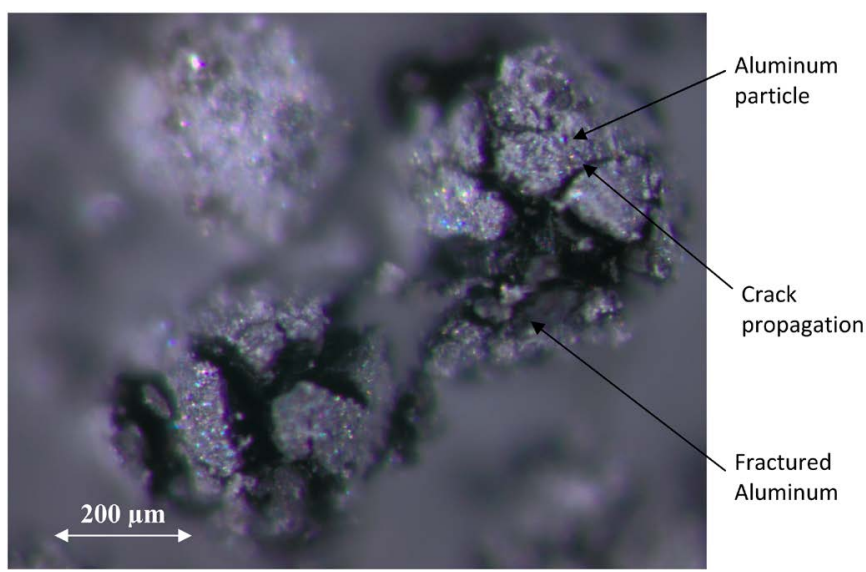

Figure 1. Crack formation on the activated aluminum particles at $\sim 30^{\circ} \mathrm{C}$. 


\subsection{Hydrogen Generation Rate}

Three micron-sized Al particles are considered in the present study, namely $30 \mu \mathrm{m}, 60 \mu \mathrm{m}$, and $350 \mu \mathrm{m}$. The hydrogen release rate is estimated at the temperatures of $30^{\circ} \mathrm{C}, 50^{\circ} \mathrm{C}$, and $90^{\circ} \mathrm{C}$. Figure 2 shows the reaction rate and the hydrogen release rate of the activated aluminum mixtures with water at $30^{\circ} \mathrm{C}$. Figures 3-6 display the plots for the hydrogen release per gram of aluminum versus time for three mixture compositions.

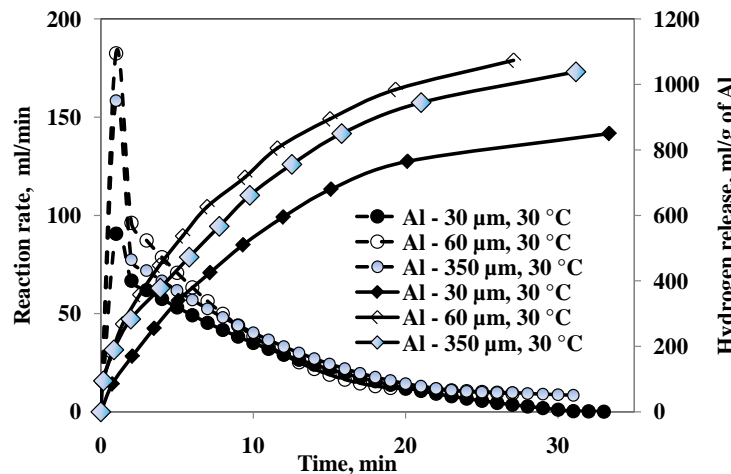

Figure 2. Reaction rate (dotted line) and hydrogen evolution rate (solid line) of the activated aluminum mixtures with water at $30^{\circ} \mathrm{C}, \mathrm{Al}-85 \%$ and Galinstan eutectics $15 \%$ by mass (Ga-In-Sn-Zn = 60-25-10-5).

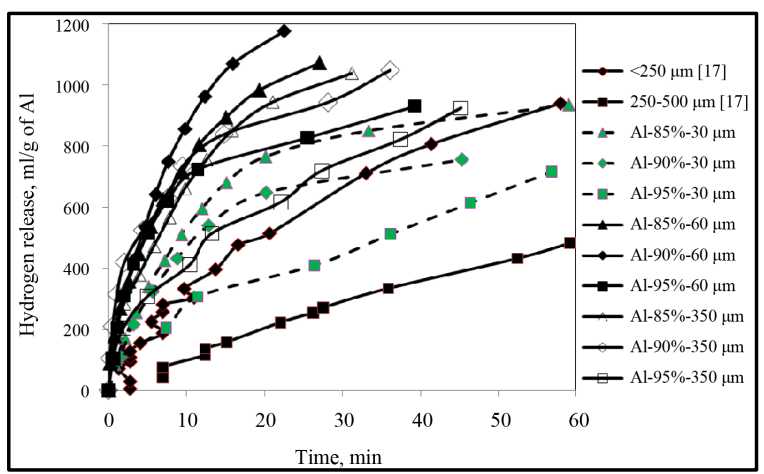

Figure 3. Comparison of hydrogen evolution rates of the activated aluminum reactions with water between the present study and Ref. [17] (the curves for the largest particle sizes).

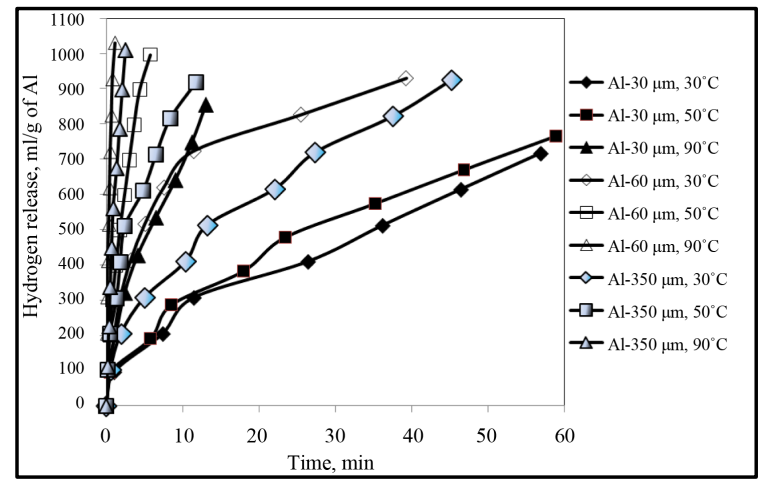

Figure 4. Hydrogen evolution rate of the activated aluminum mixtures with water, Al-95\% and Galinstan eutectics $-5 \%$ by mass (Ga-In-Sn-Zn $=60-25-10-5$ ). 


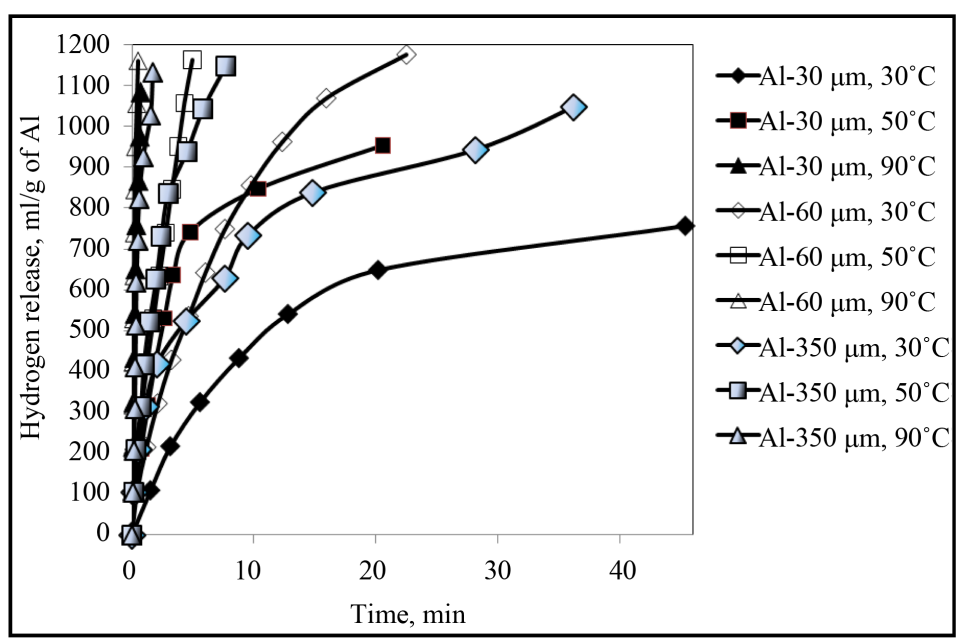

Figure 5. Hydrogen evolution rate of the activated aluminum mixtures with water, Al-90\% and Galinstan eutectics $10 \%$ by mass (Ga-In-Sn-Zn = 60-25-10-5).

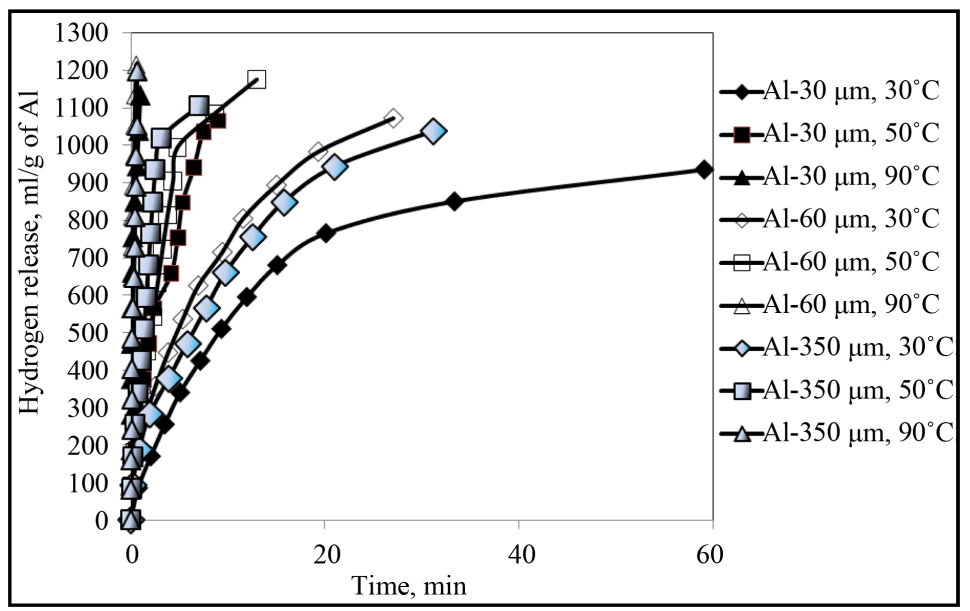

Figure 6. Hydrogen evolution rate of the activated aluminum mixtures with water, Al-85\% and Galinstan eutectics $15 \%$ by mass (Ga-In-Sn-Zn = 60-25-10-5).

\subsubsection{Effect of Al Particle Size}

Figures 2-6 show that the smaller-sized (30 $\mu \mathrm{m})$ aluminum particles display lower reaction rates than biggersized $(60 \mu \mathrm{m}$ and $350 \mu \mathrm{m})$ particles, but especially for low reaction temperatures and low galinstan contents. For larger particles (from larger than $1 \mathrm{~mm}$ to smaller than $0.25 \mathrm{~mm}$ ), the results of Ref. [17] show a gradual increase of the reaction rate and hydrogen yield with decreasing powder size. The present results show a much smaller hydrogen release rate for $30 \mu \mathrm{m}$ particles compared to both $60 \mu \mathrm{m}$ and $350 \mu \mathrm{m}$ particles. The differences in the hydrogen release rate for these last two sizes are much smaller. As particle sizes are decreased, the specific surface area is increased. This feature enables to enlarge the exposure area of the particle. However, even though the smaller particles have high reaction potential due to their larger specific surface area, the larger mass percentage of the alumina layer on the passivated aluminum particles hinders the reaction at normal ambience conditions. With the fixed amount of galinstan eutectic content, a thinner film is formed on the smaller-sized particles, compared with the formation of a thicker film on the bigger-sized particles. So, the penetration intensity of galinstan eutectic is low for smaller-sized aluminum particles, and hence its activation potential. Here, the galinstan eutectic activation mechanism plays a dual role; it cracks and removes the alumina layer and forms cracks on the aluminum core. So, both processes are weakened for smaller-sized particles and the hydrogen 
generation rate also weakens. The activation mechanism mainly depends on the specific surface area of the aluminum particles but the new results for small particles shown here also indicate that an optimum particle size exists for hydrogen generation using activated aluminum and water reactions.

\subsubsection{Effect of Galinstan Eutectics Content}

Figures 4-6 correspond to 95\%, 90\%, and $85 \%$ (by mass) Al content systems respectively. The penetration of galinstan eutectics into the aluminum grain boundaries forms a thin layer which may reduce the aluminum reactivity with water. But, the mechanical strength of the aluminum is also reduced and the water diffusion rate into the aluminum grain increases hence the aluminum particles oxidization rate. Figure 4 shows that the yield of hydrogen is $1030 \mathrm{ml}$ and 1010 of $\mathrm{H}_{2}$ per gram of aluminum at $90^{\circ} \mathrm{C}$ for $60 \mu \mathrm{m}$ and $350 \mu \mathrm{m}$ particles respectively, compared to the theoretical yield of $1244 \mathrm{ml}$ of hydrogen per gram of aluminum. However, $\mathrm{H}_{2}$ yield is much less for $30 \mu \mathrm{m}$ particles. Subsequent increases in galinstan eutectic content in the mixture improve the hydrogen yield to $1161 \mathrm{ml}$ and $1130 \mathrm{ml}$ of $\mathrm{H}_{2}$, and $1214 \mathrm{ml}$ and $1197 \mathrm{ml}$ of $\mathrm{H}_{2}$ at $90^{\circ} \mathrm{C}$, for $60 \mu \mathrm{m}$ and $350 \mu \mathrm{m}$ particles, respectively (Figure 5 and Figure 6). These figures are comparable with the earlier reports [16] [17]. It is therefore clearly evidenced that increases in galinstan eutectic content improve the hydrogen yield which demonstrates the completeness of the reaction. The reaction between the aluminum and water proceeds until the galinstan eutectics penetrates into aluminum grain and also generates a thin film on the aluminum grain. Therefore, there should be a minimum galinstan eutectic content requirement to complete the penetration process which also varies with particle size. Consequently, the higher galinstan eutectic content (15\%) in the reactants generates a hydrogen yield which is $97.5 \%$ of the theoretical value. Further inclusion of galinstan eutectics in the mixture is not necessary for $60 \mu \mathrm{m}$ and $350 \mu \mathrm{m}$ aluminum particles. But, for smaller particles $(<60 \mu \mathrm{m})$, the galinstan eutectic content should be increased beyond $15 \%$ by mass to maximize the hydrogen yield.

\subsubsection{Effect of Reaction Temperature}

The hydrogen generation rate is drastically increased when the reaction temperature is raised from $30^{\circ} \mathrm{C}$ to $90^{\circ} \mathrm{C}$ as seen in Figures 4-6. Bennett and Pinnel [12] have analyzed the solid products of aluminum and water reactions at different temperatures. The differences in the final products may be due to the variations in the reaction rate and its dependency on the reaction temperature. The galinstan eutectics penetration and diffusion rates also improve when the reaction temperature increases, hence the aluminum reactivity increases. In addition, the reaction rates are also temperature dependent. Consequently, the above overall effects significantly increase the hydrogen generation rate at high temperature conditions.

\section{Conclusion}

The present work confirms that aluminum particles reactions with water are activated using galinstan eutectics. This metal eutectic penetrates into the alumina layer, forms cracks on the alumina and the surface boundary of the aluminum particles which reduces the mechanical strength of the aluminum and activates the aluminum surface for further reactions. Due to its higher specific surface and insufficient galinstan eutectic content on the surface, the smaller-sized aluminum $(30 \mu \mathrm{m})$ particles exhibit lower hydrogen generation rate than bigger-sized aluminum (60 and $350 \mu \mathrm{m}$ ) particles. With 15\% galinstan eutectic by mass for $60 \mu \mathrm{m}$ aluminum particles, $97.5 \%$ of hydrogen yield is achieved. The galinstan eutectic content should be increased beyond $15 \%$ by mass to maximize the hydrogen yield for smaller particles $(<60 \mu \mathrm{m})$. The increase in reaction temperature improves the hydrogen generation rate and the hydrogen yield. Therefore, optimum combinations exist between the particle size, galinstan content and reaction temperature to maximize the hydrogen reaction rate and yield, depending on the hydrogen generation needs and type of applications.

\section{Acknowledgements}

This work was supported by the CNRS and the Science and Technology Service of the French Embassy in India (CEFIPRA).

\section{References}

[1] Tarasov, B.P. and Lototskii M.V. (2007) Hydrogen Energetics: Past, Present, Prospects. Russian Journal of General 
Chemistry, 77, 660-675. http://dx.doi.org/10.1134/S1070363207040299

[2] Lymberopoulos, N. (2007) Hydrogen from Renewable. In: Sheffield, J.W. and Sheffield, C., Eds., Assessment of Hydrogen Energy for Sustainable Development (NATO Science for Peace \& Security Series C: Environmental Security), Springer, Netherlands, 51-57. http://dx.doi.org/10.1007/978-1-4020-6442-5_4

[3] Tsygankov, A. (2007) Biological Generation of Hydrogen. Russian Journal of General Chemistry, 77, 685-693. http://dx.doi.org/10.1134/S1070363207040317

[4] Yokoyama, H., Waki, M., Moriya, N., Yasuda, T., Tanaka, Y. and Haga, K. (2007) Effect of Fermentation Temperature on Hydrogen Production from Cow Waste Slurry by Using Anaerobic Microflora within the Slurry. Applied Microbiology and Biotechnology, 74, 474-483. http://dx.doi.org/10.1007/s00253-006-0647-4

[5] Reddy, R.G. (2006) Fuel Cell and Hydrogen Economy. Journal of Materials Engineering and Performance, 15, 474-483. http://dx.doi.org/10.1361/105994906X117332

[6] Windes, W.E., Smith, C., Wendt, D., Erickson, A., Walraven, J. and Lessing, P.A. (2007) Electrode Coatings for High Temperature Hydrogen Electrolysis. Journal of Materials Science, 42, 2717-2723.

http://dx.doi.org/10.1007/s10853-006-1406-8

[7] Afgan, N.H. and Carvalho, M.G. (2007) Hydrogen Energy System for Sustainable Development. In: Sheffield, J.W. and Sheffield, C., Eds., Assessment of Hydrogen Energy for Sustainable Development (NATO Science for Peace \& Security Series C: Environmental Security), Springer, Netherlands, 187-209. http://dx.doi.org/10.1007/978-1-4020-6442-5_16

[8] Troczynski, T. and Czech, E. (2005) Compositions and Methods for Generating Hydrogen from Water. US Patent No. 2005/0232837 Al. 2005. http://www.freshpatents.com/-dt20081225ptan20080317665.php

[9] Trenikhin, M.V., Kozlov, A.G., Nizovskii, A.I., Drozdov, V.A., Lavrenov, A.V., Bubnov, A.V., Finevich, V.P. and Duplyakin, V.K. (2007) Activated Aluminum: Features of Production and Application in the Synthesis of Catalysts for Pertochemistry and Oil Processing. Russian Journal of General Chemistry, 77, 2320-2327. http://dx.doi.org/10.1134/S1070363207120377

[10] Wang, H.Z., Leung, D.Y.C., Leung, M.K.H. and Ni, M. (2009) A Review on Hydrogen Production Using Aluminum and Aluminum Alloys. Renewable and Sustainable Energy Reviews, 13, 845-853. http://dx.doi.org/10.1016/j.rser.2008.02.009

[11] Trenikhin, M.V., Bubnov, A.V., Kozlov, A.G., Nizovskii, A.I. and Duplyakin, V.K. (2006) The Penetration of Indium-Gallium Melt Components into Aluminum. Russian Journal of Physical Chemistry A, 80, 1110-1114. http://dx.doi.org/10.1134/S0036024406070193

[12] Bennett, J.E., Pinnel, M.R. (1973) Reactions between Mercury-Wetted Aluminum and Liquid Water. Journal of Materials Science, 8, 1189-1193. http://dx.doi.org/10.1007/BF00632772

[13] Sheindlin, A.E. and Zhuk, A.Z. (2007) Concept of Aluminum Hydrogen Energy Industry. Russian Journal of General Chemistry, 77, 778-782. http://dx.doi.org/10.1134/S107036320704038X

[14] Soler, L., Macanas, J., Munoz, M. and Casado, J. (2007) Aluminum and Aluminum Alloys as Sources of Hydrogen for Fuel Cell Applications. Journal of Power Sources, 169, 144-149. http://dx.doi.org/10.1016/j.jpowsour.2007.01.080

[15] Sarou-Kanian, V., Ouazar, S., Escot Bocanegra, P., Chauveau, C. and Gökalp, I. (2007) Low Temperature Reactivity of Aluminum Nanopowders with Liquid Water. Proceedings of the 3rd European Combustion Meeting ECM 2007, Chania, 11-13 April 2007.

[16] Kravchenko, O.V., Semenenko, K.N., Bulychev, B.M. and Kalmykov, K.B. (2005) Activation of Aluminum Metal and Its Reaction with Water. Journal of Alloys and Compounds, 397, 58-62. http://dx.doi.org/10.1016/j.jallcom.2004.11.065

[17] Parmuzina, A.V. and Kravchenko, O.V. (2008) Activation of Aluminium Metal to Evolve Hydrogen from Water. International Journal of Hydrogen Energy, 33, 3073-3076. http://dx.doi.org/10.1016/j.ijhydene.2008.02.025

[18] Ilyukhina, AV., Kravchenko, O.V., Bulychev, B.M. and Shkolnikov, E.I. (2010) Mechanochemical Activation of Aluminum with Gallams for Hydrogen Evolution from Water. International Journal of Hydrogen Energy, 35, 1905-1910. http://dx.doi.org/10.1016/j.ijhydene.2009.12.118

[19] Hugo, R.C. and Hoagland, R.G. (1998) In-Situ TEM Observation of Aluminum Embrittlement by Liquid Gallium. Scripta Materialia, 38, 523-529. http://dx.doi.org/10.1016/S1359-6462(97)00464-8 